\title{
scripted
}

Volume 15, Issue 1, August 2018

\section{Law as a User: Design, Affordance, and the Technological Mediation of Norms}

\author{
Laurence Diver* \\ (ㄷ) (1) $(9)$ \\ (C) 2018 Laurence Diver \\ Licensed under a Creative Commons Attribution-NonCommercial- \\ NoDerivatives 4.0 International (CC BY-NC-ND 4.0) license
}

DOI: $10.2966 /$ scrip.150118.4

\begin{abstract}
Technology law scholars have recently started to consider the theories of affordance and technological mediation, imported from the fields of psychology, human-computer interaction (HCI), and science and technology studies (STS). These theories have been used both as a means of explaining how the law has developed, and more recently in attempts to cast the law per se as an affordance. This exploratory paper summarises the two theories, before considering these applications from a critical perspective, noting certain deficiencies with respect to potential normative application and definitional clarity, respectively. It then posits that in applying them in the legal context we should seek to retain the relational user-artefact structure around which they were originally conceived, with the law cast as the user of the artefact, from which it seeks certain features or outcomes. This approach is effective for three reasons. Firstly, it acknowledges the power imbalance between law and architecture, where the former is manifestly subject to the decisions, made by designers, which mediate and transform the substance of the legal norms they instantiate in technological artefacts. Secondly, from an analytical perspective, it can help avoid some of the conceptual and definitional problems evident in the nascent legal literature on affordance. Lastly, approaching designers on
\end{abstract}


their own terms can foster better critical evaluation of their activities during the design process, potentially leading to more effective 'compliance by design' where the course of the law's mediation by technological artefacts can be better anticipated and guided by legislators, regulators, and legal practitioners.

\section{Keywords}

affordance, technological mediation, postphenomenology, legal theory, compliance by design, legal design

* University of Edinburgh School of Law, Edinburgh, Scotland, laurence.diver@ed.ac.uk 
For what is law with respect to the computer if not a user itself? ${ }^{1}$

\section{Introduction}

Technology law scholars have recently started to consider the theories of affordance and technological mediation. This is a welcome development, showing a sensitivity to the inherently cross-disciplinary nature of both normative and positive enquiries into technology regulation. These theories have been used to explain how the technologies which embody law have affected its development, and more recently in attempts to cast the law as an affordance per se. The success of these approaches has been mixed. Controversies in the literature on affordance theory around definitional clarity and breadth of application are apt to be repeated in the legal sphere if the concept is not used with care.

In an effort to avoid some of these problems, this exploratory paper contributes to the burgeoning legal literature in this area whilst remaining faithful to the two theories' origins in the world of material artefacts and their design. The locus of the enquiry is the field of 'compliance by design', which is concerned with ensuring the design of technical architectures is faithful to, or isomorphic with, legal and regulatory norms. ${ }^{2}$ A major issue is how, as nonlawyers, designers can integrate an appropriate sensitivity to the law within their processes. The concept of affordance already has a significant presence in the design sphere, so its consideration from a legal perspective might suggest one

1 Cornelia Vismann and Markus Krajewski, “Computer Juridisms" [2007] Grey Room 90-109, p. 101.

2 For a discussion of the concept of isomorphism, or "well defined correspondence" between the legal and technological domains, see Trevor Bench-Capon and Frans Coenen, "Isomorphism and Legal Knowledge Based Systems" (1992) 1 Artificial Intelligence and Law 65-86. 
mechanism by which this challenge could be met: if lawyers adopt design language and concepts in their critiques of technological artefacts, we might move a step towards bridging the gap between these separate but fundamentally intertwined worlds.

The paper builds on Mireille Hildebrandt's work on "legal protection by design", in her discussion of which she refers only in passing to "detecting, configuring or designing affordances that are compatible with specific legal norms". ${ }^{3}$ Here I sustain the focus on the concepts of affordance and mediation, taking it beyond Hildebrandt's seminal analysis of the technological embodiment of law and the increasing threat it poses to legality.

I begin by summarising affordance theory and technological mediation with a view to avoiding the definitional confusion that has been evident in the legal treatment of these concepts - if they are to provide a fruitful means of interfacing between the worlds of design and law, clarity from the outset is a necessity. In light of that analysis, I then consider how code is both more, and less, than law. This leads me to the first argument of the paper: that code's characteristics render law merely a user of technological artefacts. From that perspective, we can come full circle to an understanding of law which fits into the relational analytical framework of affordance and mediation theory, asking what it is that a particular technological artefact affords (or should afford) the law-as-(mere)-user when it mediates the operation of the latter through the materialities of its architecture.

3 Mireille Hildebrandt, Smart Technologies and the End(s) of Law (London: Edward Elgar Publishing, 2015), p. 218. 


\section{Affordance}

The facilitation of a particular action or behaviour by an artefact's design to a particular user is known as an 'affordance'. The concept was originally developed in the late 1960s by the perceptual psychologist James Gibson, who defined affordance as what an artefact "offers the animal, what it provides or furnishes, either for good or ill." ${ }^{4}$ It was later developed and introduced into the design sphere by Donald Norman, who defines it as "a relationship between the properties of an object and the capabilities of the agent that determine just how the object could possibly be used." ${ }^{5}$ Individual affordances can be both positive and negative, which is to say beneficial and injurious to the user, ${ }^{6}$ each to varying degrees. Gibson is careful to avoid the value judgements suggested by the terms "positive" and "negative", stating instead that such descriptions can be applied objectively if "their meanings are pinned down to biological and behavioural facts". So, for example, a fire can afford both the warmth that is necessary to life, but it can also afford burning, which implies injury and, potentially, death. ${ }^{7}$ The extent of the benefit or injury will depend on the user in question. Affordances are therefore not objective physical properties of the artefact, but rather they arise on-the-fly through the relationship between it and a particular user, as governed by those properties. Gibson illustrates this relationship through the examination of a hypothetical walking surface:

4 James Gibson, The Ecological Approach to Visual Perception (Classic Edition, New York: Psychology Press, 2015), p. 119 (emphasis supplied). The concept originated in Gibson's The Senses Considered as Perceptual Systems (Boston, Mass.: Houghton Mifflin, 1966).

5 Donald Norman, The Design of Everyday Things (Cambridge, Mass.: MIT Press, 2013), p. 11.

6 Although Gibson was concerned with organisms generally (see the quote infra), humans are the agents with which I am concerned, and so I hereafter I use the term 'users'.

7 Gibson, supra n. 4, pp. 128-129. 
Note that the four properties listed - horizontal, flat, extended, and rigid would be physical properties of a surface if they were measured with the scales and standard units of physics. As an affordance of support for a species of animal, however, they have to be measured relative to the animal. They are unique for that animal. They are not just abstract physical properties. They have unity relative to the posture and behaviour of the animal being considered. So an affordance cannot be measured as we measure in physics. ${ }^{8}$

Thus, a surface that affords support to a domestic cat (it is "walk-on-able"9) may or may not do the same to an adult elephant; the particular mix of physical properties and the size and weight of both animals will determine which animal is afforded what capabilities. It can be seen, then, how the concept highlights the inherent and simultaneous objectivity and subjectivity of an artefact's potential effects in the world. As Norman puts it,

[t]he presence of an affordance is jointly determined by the qualities of the object and the abilities of the agent that is interacting. This relational definition of affordance gives considerable difficulty to many people. We are used to thinking that properties are associated with objects. But affordance is not a property. An affordance is a relationship. Whether an affordance exists depends on the properties of both the object and the agent. ${ }^{10}$

Importantly, an affordance need not be perceived in order to exist; it is an objective fact about how the properties of the artefact and the user relate to one

$8 \quad$ Ibid., p. 120 (emphasis supplied).
9 Ibid., p. 119.

10 Norman, supra n. 5, p. 11 (my emphasis). 
another. ${ }^{11}$ Affordances are potentials that may not be within the user's awareness and may never be realised, but nevertheless the relationship is always present and ready to be acted upon for as long as the properties necessary for it obtain in both the artefact and the user. ${ }^{12}$

This is what Norman has subsequently referred to as real, as opposed to perceived, affordances. ${ }^{13}$ For example, a particular fruit may afford nutrition to a particular species of animal, but if the animal is unaware of this the relationship will never be fulfilled, despite its extant potentiality. Perceived affordances are those which the user 'picks up on', which, as the example just given demonstrates, do not necessarily represent the full range of relationships that exist between her and the artefact in question. The distinction is important in the online context because, as Norman puts it, "in graphical, screen-based interfaces, the designer primarily can control only perceived affordances [because] the computer system already comes with built-in physical [i.e. real] affordances" ${ }^{14}$ Although Norman is not approaching the question primarily with the underlying instrumentality of software (as opposed to visual) design in mind, his comment hints at an important truth about the power of the designer to control users'

11 Ibid., p. 13. In an interesting discussion of robotics and artefact-artefact affordances, Maier and Fadel discuss how non-organic agents can be afforded support by a surface, without 'knowing' (perceiving) it. See Jonathan Maier and George Fadel, "Affordance-Based Methods for Design", Proceedings of the 2003 International Design Engineering Technical Conferences and Computers and Information in Engineering Conference (Chicago, Illinois: The American Society of Mechanical Engineers, 2003), p. 2.

12 See Peter Nagy and Gina Neff, "Imagined Affordance: Reconstructing a Keyword for Communication Theory" (2015) 1 Social Media + Society 1-9, p. 3, and Samer Faraj and Bijan Azad, "The Materiality of Technology: An Affordance Perspective" in Paul Leonardi, Bonnie Nardi and Jannis Kallinikos (eds.), Materiality and Organizing: Social Interaction in a Technological World (Oxford: OUP, 2012), pp. 250-251.

13 Donald Norman, "Affordance, Conventions, and Design" (1999) 6 Interactions 38-43.

14 Ibid., p. 39. The potential discrepancy between real and perceived affordances is perhaps even more marked in the screen-less devices that are proliferating as part of the Internet of Things. 
perceptions through the choices they make when they constitute the interface. The corollary of this is that in controlling those surface perceptions of what is possible, other underlying, or real, affordances can be hidden from sight (for example the ability to view and alter source code, or to submit fake details to a registration system), or their hypothetical, imagined possibility supressed altogether (for example where users accept the default settings of a technical artefact without enquiring as to how the available options might better suit their preferences or interests $\left.{ }^{15}\right)$.

\subsection{Disaffordance}

This notion of the positivity or negativity of affordances discussed above refers to the outcome occasioned by the affordance. This should be distinguished from both (i) the objective fact that interaction is prevented and the relationship therefore does not exist, in what Norman terms an "anti-affordance", 16 and (ii) the subjective misapprehension as to the existence of that relationship, where the user misinterprets the information she is receiving and believes there to be a relationship between herself and the artefact when in fact there is none (or not the one she believes there to be). Both Gibson and Norman provide the example of a glass pane covering an opening, which gives the user the erroneous impression of the affordance of passage, while the other (Norman's "antiaffordance") points simply to the objective fact that there is no such affordance, whether the user is aware of this or not. ${ }^{17}$

\footnotetext{
15 Jay Kesan and Rajiv Shah, "Setting Software Defaults: Perspectives from Law, Computer Science and Behavioral Economics" (2006) 82 Notre Dame Law Review 583-634.

16 Norman, supra n. 5, p. 11.

17 Gibson, supra n. 4, pp. 133-134; Norman, supra n. 5, pp. 11-12.
} 
Interaction designer Dan Lockton draws on Lawrence Lessig's discussion of "architectures of control" 18 to take the notion of anti-affordances further, adding the element of intention that is absent in Norman's discussion. Lockton defines "architectures of control" as

features, structures or methods of operation designed into any planned system with which a user interacts, which are intended to enforce or restrict certain user behaviour. ${ }^{19}$

Lockton discusses disaffordance in the context of DRM, including the Sony BMG scandal of the mid-2000s, which of course animated a great deal of legallyrelevant scholarship. ${ }^{20}$ This topic will be returned to below in part 5.2.

Re-iterating the original definition, Gibson's negative affordance is concerned with the 'ill' that is offered, provided, or furnished by the artefact. Norman's anti-affordance is concerned with the bare fact of the absence of a particular offering, provision, or furnishing by the artefact. Lockton, however, is interested less in the ex post outcome of the affordance's operation per se, focusing instead on the ex ante intent behind the design. 'Positive' and 'negative' in this sense are not a Gibsonian judgement of the quality of the outcome, but rather an assessment of the behaviour(s) that the affordance enables or restricts. It is 'positivity' in the juristic sense of referring to an extant rule: what is ex ante permitted versus what is not. For Lockton, this sense of 'negative' is thus about

18 Lawrence Lessig, Code: Version 2.0 (New York: Basic Books, 2006), ch. 4.

19 Dan Lockton, "Architectures of Control in Product Design" [2006] Engineering Designer: The Journal of the Institution of Engineering Designers 28-31.

20 See for example Deirdre Mulligan and Aaron Perzanowski, "The Magnificence of the Disaster: Reconstructing the Sony BMG Rootkit Incident" (2007) 22 Berkeley Technology Law Journal 1157-1232; J. Alex Halderman and Edward Felten, "Lessons from the Sony CD DRM Episode" [2006] 15th USENIX Security Symposium 77-92. 
the engineering of obedience. ${ }^{21} \mathrm{He}$ suggests the term 'disaffordance' to describe these constraints, which he defines as "either products with functionality deliberately removed... or with the functionality deliberately hidden or obscured to reduce users' ability to use the product in certain ways, or a combination of the two." 22 Thus, disaffordances are intentional and strategic, as opposed to inadvertent or the result of incompetent design. There is therefore a value judgement attached to them in a way which Gibson explicitly, and Norman implicitly, avoid. Although the term 'disaffordance' has gained only modest traction, it is instructive in encapsulating the idea of how an artefact can conceal, discourage, or forbid the possibility of certain behaviours as a result of design decisions. $^{23}$

The idea of there being a spectrum of behavioural possibilities or limitations fits with recent work on affordance theory done by sociologists Jenny Davis and James Chouinard. Their framework of six "affordance mechanisms" aims to cut through a definitional confusion in the literature ${ }^{24}$ resulting perhaps from the abstractness of the original theory and its tendency to promote binary

21 Dan Lockton, "Disaffordances and Engineering Obedience" (2006), available at http://architectures.danlockton.co.uk/2006/10/22/disaffordances-and-engineering-obedience/ (accessed 3 February 2018).

22 Ibid.

23 See $i b i d$. D.E. Wittkower makes a similar point, written from the perspective of avoiding unethical discrimination in design. See D.E. Wittkower, "Principles of Anti-Discriminatory Design", 2016 IEEE International Symposium on Ethics in Engineering, Science and Technology (ETHICS) (IEEE, 2016), p. 2. For a discussion of disaffordances in the robotics context, see Mohan Sridharan and Ben Meadows, "Towards an Architecture for Discovering Domain Dynamics: Affordances, Causal Laws, and Executability Conditions", International Workshop on Planning and Robotics (PlanRob) at the International Conference on Automated Planning and Scheduling (ICAPS) (Pittsburgh: Association for the Advancement of Artificial Intelligence, 2017). James Gee discusses disaffordance in the context of video game worlds, noting how they are designed explicitly with particular mixes of affordance and disaffordance in mind, vis-à-vis the player's avatar. See James Gee, "Pleasure, Learning, Video Games, and Life: The Projective Stance" (2005) 2 E-Learning and Digital Media 211-223, p. 212.

24 Jenny Davis and James Chouinard, "Theorizing Affordances: From Request to Refuse" (2016) 36(4) Bulletin of Science, Technology \& Society 241-248. 
thinking which may have enabled subsequent scholarship to add unhelpful texture to the concept. Although Davis and Chouinard concede that this confusion has led to suggestions that the concept has lost any intellectual value it might have had, ${ }^{25}$ I share their optimism that it might still assist us in analysing artefacts and their material relationality. ${ }^{26}$ This is perhaps especially true in the legal sphere, where its application is almost entirely novel and where there might therefore be useful insights to be gained. ${ }^{27}$ Indeed, the contribution of those authors seems a particularly apt mechanism for applying the theory anew, since it cuts through the definitional uncertainty in the literature to provide what they suggest is a "nuanced and dynamic model" that can facilitate "complex analyses of subject-artifact relationships" ${ }^{28}$

The framework Davis and Chouinard develop posits that affordance exists on a spectrum, where any given example is not a singular binary fact but rather operates by degree. They give the example of a set of stairs which can afford easy or difficult climbing depending on the angle of their construction. This is in opposition to the 'classic' concept of affordance, which would have it

25 See, for example, Martin Oliver, "The Problem with Affordance" (2005) 2 E-Learning and Digital Media 402-413.

26 Davis and Chouinard, supra n. 24, p. 241.

27 Hildebrandt notes that Ryan Calo is "one of the very few lawyers who has written about law in terms of affordances". See Mireille Hildebrandt, "Law As an Affordance: The Devil Is in the Vanishing Point(s)" (2017) 4(1) Critical Analysis of Law 116-128, p. 121. Calo in turn cites Hildebrandt's work (referenced here et passim) and Julie Cohen's book Configuring the Networked Self: Law, Code, and the Play of Everyday Practice (New Haven, Conn.: Yale University Press, 2012) as two lone examples of the use of affordance theory in a legal context where there is otherwise "next to no mention of Gibson". See his "Can Americans Resist Surveillance?" (2016) 83 The University of Chicago Law Review 23-43, p. 29. Indeed, a search conducted at the time of writing uncovered almost nothing in the legal literature beyond that published by the above scholars. One notable exception is Ronald Leenes, "Framing Techno-Regulation: An Exploration of State and Non-State Regulation by Technology" (2011) 5 Legisprudence 143-169.

28 Davis and Chouinard, supra n. 24, p. 241. 
that the stairs either simply do or do not afford climbing for a particular user. ${ }^{29}$ Davis and Chouinard suggest that affordances can be characterised as one of six mechanisms: request, demand, allow, encourage, discourage, and refuse. One can see how these mechanisms enforce the idea of relationships, which Norman noted caused such difficulty. Adding one of these modifiers adds useful depth to the bare concept of affordance, enabling a more intuitive understanding of a given user-artefact relationship. Returning the example of stairs mentioned above, they allow the able-bodied to climb, discourage careless climbing (if they are particularly steep), and refuse climbing to those who are wheelchair-bound. Here we get an immediate sense of three normative affordance relationships that exist between the artefact and three hypothetical classes of user.

Considered through these affordance mechanisms, it becomes easier to discern the particular makeup of a given artefact's set of affordance relationships. One can appreciate more easily the affordances and disaffordances of a particular artefact vis-à-vis a particular user, when one asks the questions in turn: "what does it allow?", "what is it encouraging?", etcetera. When taken together, the bundle of affordance relationships so identified, we can begin to answer a broader question: how does the technological artefact mediate reality for its user? This is the question that the field of postphenomenology is fundamentally concerned with. Both Hildebrandt and fellow technology law scholar Julie Cohen consider postphenomenology in their analyses. The former is concerned mainly with the role of "technological normativity" in the evolutionary embodiment of law, ${ }^{30}$ and the latter with the situatedness of users vis-à-vis their understanding of the networked environments they inhabit. ${ }^{31}$ Here I adopt a 'compliance by

29 Davis and Chouinard characterise this as a "false binary". See ibid., p. 242.

30 Mireille Hildebrandt, "Legal and Technological Normativity: More (and Less) than Twin Sisters" (2008) 12 Techné: Research in Philosophy and Technology 169-183, p. 177 et seq.

31 Cohen, Configuring the Networked Self, supra n. 27, pp. 48-49. 
design' perspective, from which I will cast the law-system ${ }^{32}$ as the 'user', and the substantive law as the 'reality' which that user wishes to access and oversee. The over-arching question then becomes: how does the technological artefact mediate the substantive law from the perspective of the law-system? Before moving to that discussion, I set out the salient elements of the postphenomenological view of technological mediation.

\section{Technological mediation}

Postphenomenology is an area of science and technology studies (STS) which explores the relationships between individuals and artefacts, with an emphasis on the materiality of artefacts per se and not just as elements that are subsumed in a broader, non-technological (social) assemblage. ${ }^{33}$ Peter-Paul Verbeek directs his enquiry at "the role played by specific technologies in specific contexts", ${ }^{34}$ asking what the effects are of their materiality. Drawing on Martin Heidegger, Don Ihde, Bruno Latour, and Albert Borgmann, Verbeek's work deepens our understanding of the normative role of technologies as mediators of the relationships between humans and reality, rather than as either wholly neutral or wholly deterministic. Those relationships are split into those of perception (what the user thinks she can do with the artefact) and those of action (what she can actually do with it). Technological mediation is the ongoing construction and manipulation of these two relationships by and through artefacts, the result of

32 I borrow this term from Aernout Schmidt, "Radbruch in Cyberspace: About Law-System Quality and ICT Innovation" (2009) 3 Masaryk University Journal of Law and Technology 195218 , because it evokes not a monolithic 'law' but rather a complex made up of discrete parts, evolving in relation to one another. From a compliance perspective such a holistic view is of course a normative, if aspirational, goal.

33 Peter-Paul Verbeek, What Things Do: Philosophical Reflections on Technology, Agency, and Design (Pennsylvania: Penn State Press, 2005), p. 68. For a definition of postphenomenology, see ch. 3 of the same volume.

34 Ibid., p. 7. 
which is, as postphenomenological thought has it, the co-constitution of reality. The user and the artefact, in bringing together their particular characteristics, constitute a new reality through their relationship. One can see the parallels with the theory of affordances; indeed, affordances are the individual building blocks that, taken in aggregate, make up the totality of technological mediation between a particular artefact and a particular user. ${ }^{35}$ We can conceptualise the relationship as in Figure 1 below, where the user's experience of reality is an output of the mediating function $\mathrm{TM}()$.

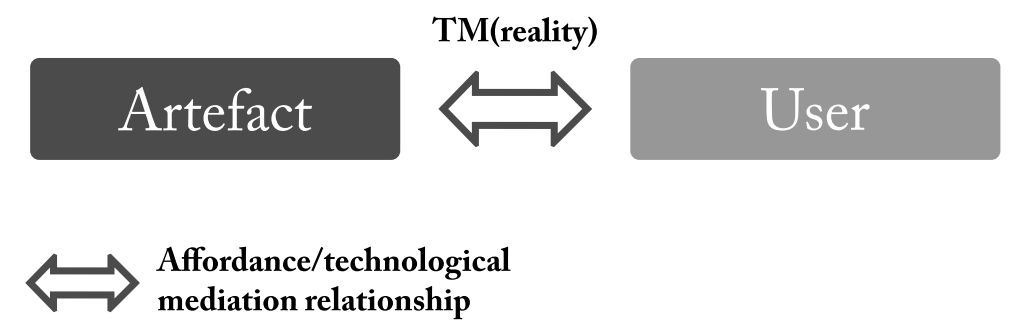

Figure 1. Artefact $\leftrightarrow$ User relationship of technological mediation

\subsection{Transformations}

The user's experience of reality is transformed by these mediating relationships. The technological mediation of perception amplifies or reduces what can be comprehended of reality, while the technological mediation of action invites or inhibits behaviour. In both cases these mediations constitute transformations of reality as it is understood by the user, demonstrating what Verbeek calls "an important aspect of the non-neutrality of technology". ${ }^{36}$

35 Asle Kiran and Peter-Paul Verbeek, "Trusting Our Selves to Technology" (2010) 23 Knowledge, Technology \& Policy 409-427.

36 Verbeek, supra n. 33, p. 131. Regarding terminology, Verbeek speaks of perception being 'transformed', while Latour talks of action being 'translated' - see Bruno Latour, "Where Are the Missing Masses? The Sociology of a Few Mundane Artifacts" in Wiebe Bijker and John Law (eds.), Shaping Technology/Building Society: Studies in Sociotechnical Change (Cambridge, Mass.: MIT Press, 1992), p. 174 and et passim. For an influential discussion of translation in 
Some examples serve to illustrate the concept. First, Ihde contrasts the technological mediation of a fountain pen and of a word processor. ${ }^{37}$ The former imposes a slower style that inclines the writer towards taking time and considering her sentences before putting pen to paper, while the latter permits something closer to the speed of the spoken word, with additional facilities that allow for the composition to be edited, moved around, and refactored efficiently and easily. Neither the pen nor the word processor determine the mode of writing - both enable writing that is anywhere between slow and considered, and fast and careless - but their respective intentionalities "promote or evoke a distinct way of writing." 38 Towards the more overtly political end of the mediation spectrum, Verbeek provides an evocative example, describing how the mayor of the Romanian city of Cluj sought to have the rakes of municipal employees shortened so that they could no longer lean against them, thus discouraging "laziness". In Verbeek's description of the situation, "[t]he rake mediates the relation between the workers and the public gardens; it is not merely a means but plays an active role in the way this relation takes shape." ${ }^{39}$ Langdon Winner's discussion of Robert Moses' bridges on Long Island suggests a similar politicisation of artefacts - in that case, the bridges were reportedly designed intentionally to be too low for public transport to pass beneath them, thus

Actor Network Theory, see Michel Callon, "Some Elements of a Sociology of Translation: Domestication of the Scallops and the Fishermen of St Brieuc Bay" (1984) 32 The Sociological Review 196-233. For my purposes, the difference in terminology is not materially relevant, hence the use of 'transformations'.

37 Don Ihde, Technology and the Lifeworld: From Garden to Earth (Bloomington, In.: Indiana University Press, 1990), p. 141 et seq.

38 Verbeek, supra n. 33, pp. 114-115 (emphasis supplied). There is an interesting contrast here with Ost's "word processor" model of law-making, whereby the copy/paste paradigm of electronic text has accelerated the proliferation of norms. For an English discussion see Florian Martin-Bariteau, "The Matrix of Law: From Paper, to Word Processing, to Wiki" (2014) 19 Lex Electronica 1-23.

39 Verbeek, supra n. 33, p. 115 (emphasis supplied). 
preventing those reliant on public transport (which at the time meant to a disproportionate degree racial minorities and those in poverty) from accessing the public beaches which the roads that ran under the bridges led to. ${ }^{40}$ The connection with disaffordance ("architectures of control" and the "engineering of obedience") is clear. This politicisation demonstrates how design can be infused with moral purpose, what Ihde terms technological intentionality, discussed next.

\subsection{Technological intentionality}

According to postphenomenology, technological intentionality has two senses. The first is the 'intention' (program of action, in Latour's language) inscribed into the artefact by its designer: Moses' bridges intend to prevent access by public transport vehicles and their passengers to public beaches; the shortened rake handles intend to prevent relaxed leaning; word processors intend the efficient and fast (re-)composition of texts. This first sense refers to "a certain directionality, inclination or trajectory that shapes the ways in which [artefacts] are used." 41

The second, hermeneutic, sense is more holistic. It points to how the human-world relationship is mediated by the artefact, and is concerned with the idea that humans and their worlds are co-constitutive. The individual's sense of her own agency, and of the possibilities in the world which that agency can interact with, are mediated by the artefact, thus blurring the line between

\footnotetext{
40 Langdon Winner, "Do Artifacts Have Politics?" [1980] Daedalus 121-136. Although Winner's account of the Long Island bridges has been challenged, his example nevertheless effectively demonstrates the concept.

${ }_{41}$ Verbeek, supra n. 33, p. 114.
} 
subjectivity and objectivity. ${ }^{42}$ When she sets out to achieve something, her perception of what she can do and what the world permits are mediated by the artefact, and thus so too are her understanding of her self and her world coconstituted through the lens of that mediation. ${ }^{43}$ 'The world' here is not an external truth; rather it is constituted by the particular individual who lives in it, as she is by it. The operation is mutual and bi-directional - she makes her world and her world makes her, and that 'making' is nudged this way or that by the technological mediation of artefacts. As Verbeek puts it, “[w]hat humans are and what their world is receive their form by artifactual mediation... [h] umans and the world they experience are the products of technological mediation, and not just the poles between which the mediation plays itself out." ${ }^{44}$ We can gain a better understanding of the structure and effects of an artefact by considering it from a relational, rather than merely a functional, perspective. Affordance and mediation provide tools to help achieve this. ${ }^{45}$

\subsection{Affordance and mediation}

One can appreciate how the concept of technological mediation relates to affordance. ${ }^{46}$ Both real and perceived affordances are evidence of the second

42 Shedding the 'modern' dichotomy of subject/object is a prime goal of postphenomenology and of Actor Network Theory. See ibid., p. 161 et seq. See also Faraj and Azad, supra n. 12, pp. 237-238. Again, parallels with affordance theory arise: Gibson explains that "an affordance is neither an objective property nor a subjective property; or it is both if you like". See Gibson, supra n. 4, p. 121.

43 Verbeek, supra n. 33, p. 116. This echoes Julie Cohen's suggestion that "as we struggle to shape our technologies and configure our artifacts, they also and quite literally configure us". See Cohen, Configuring the Networked Self, supra n. 27, p. 27.

44 Verbeek, supra n. 33, p. 130.

45 Maier and Fadel discuss the deficiencies of 'functional' theories of design, and how a 'relational', or affordance-based, theory, is more apt to explain the structure and effects of an artefact. See Jonathan Maier and Georges Fadel, "Affordance Based Design: A Relational Theory for Design" (2009) 20 Research in Engineering Design 13-27.

46 See Kiran and Verbeek, supra n. 35. 
(hermeneutic) form of technological intentionality, where the artefact mediates the individual's understanding of what she can do in the world as she perceives it. Real (dis)affordances are also, of course, the bread and butter of the first form of technological intentionality: to inscribe a particular course of action in the artefact it must afford that course of action for a particular user or class of users; similarly, to proscribe a particular course of action, the designer must disafford it for a particular user or class of users, as with the Long Island bridges or the shortened rake handles. The existence of an affordance is an objective fact about the relationship between a particular artefact and individual in a particular context, which when taken in aggregate with any other (dis)affordance results in a particular normative assemblage of technological mediation. And, as discussed above, affordances are not fixed attributes of an artefact, rather they come about as relations between particular artefacts and particular individuals in particular contexts. The affordance is an extant fact while it persists, but affordances change and mutate constantly in response to the evolution of their various ingredients.

This connects closely with the second postphenomenological sense of intentionality which speaks to the co-constituting relation between the individual and the artefact. ${ }^{47}$ Thus, affordances can be seen as the underlying building blocks of mediation; they are one way of thinking about and labelling the 'scripts' which, through their translating mechanism, come together in aggregate to make up the mediating power of the artefact in the co-constitutive relationship between the user and the world. Whereas affordances are neutral facts, when they come together in this way they gain normative significance when considered through the postphenomenological lens of technological mediation.

47 Ibid., p. 415 et seq. 


\section{Law and affordances}

Recent work bringing affordance and postphenomenological theory into the legal sphere represents a welcome development in technology law scholarship, demonstrating a greater willingness to interface with other disciplines in the pursuit of better understanding and normative outcomes. As Julie Cohen has stated, "one cannot explain how code regulates - and, critically, how it comes to regulate one way or another - without harnessing the insights of STS." 48

\subsection{Law as an affordance per se}

In a recent article on United States government surveillance, Ryan Calo seeks to cast law itself as an affordance, along with politics, technological architecture, and social norms. He pushes the concept directly into the legal sphere thus:

...the law itself represents a set of affordances. Individuals or groups can turn to the law for recourse or find themselves at risk because others have done so. Legal affordances have the same basic features that I have already described. You can realize or fail to realize that you have recourse at law. You can think that you have recourse at law but be wrong. And, of particular interest to this Essay, not every person has the same legal affordances, even when a violation of law has clearly occurred..$^{49}$

In the same paper, he applies the theory to the market, architecture (the technological section), and norms. Those conversant in the literature on software regulation will immediately recognise the four Lessigian "regulatory modalities"

48 Cohen, Configuring the Networked Self, supra n. 27, p. 27.

49 Calo, "Can Americans Resist Surveillance?", supra n. 27, p. 29. 
in the way Calo groups his consideration of affordances. ${ }^{50}$ It is not clear why he does so, especially since Calo himself agrees that the four modalities are limited, and that "obviously missing are many other means of action and expression, such as art, protest, civil disobedience, and education". ${ }^{51}$ If we are to adopt STS perspectives in our consideration of how software regulates, as Cohen suggests we should, it is incumbent that we cast off the liberal lens of the New Chicago School, and instead adopt not just agnostic perspectives on sources of regulation but also ones which are sensitive to context and the situatedness of the actors involved. ${ }^{52}$ This is the aim of theories of technology, including affordances, actor network theory (ANT), and postphenomenology, which seek to identify the actual material effects of artefacts in particular contexts, eschewing any overarching ideological viewpoint..$^{53}$

Although Calo is explicitly concerned with the law per se as an affordance, rather than with what technological artefacts afford it (as is the approach of this paper), it is nonetheless instructive to consider his analysis. Unfortunately, he runs almost immediately into a methodological obstacle. Discussing the courts, he suggests that "in theory, then, courts afford individuals and groups a number of ways to challenge surveillance." 54 To query properly what a court affords, at a level which means more than simply "provide", would require in-depth analysis across many fields of enquiry - not just the substance of the norms being litigated in that court, but also for example economic considerations (the socioeconomic

50 Lawrence Lessig, 'The New Chicago School' (1998) 27 The Journal of Legal Studies 661-691. The four regulatory modalities are most famously set out in Lessig's Code and Other Laws of Cyberspace (New York, N.Y.: Basic Books, 1999) and its second edition Code: Version 2.0 (New York, N.Y.: Basic Books, 2006), ch. 7.

51 Calo, "Can Americans Resist Surveillance?", supra n. 27, pp. 30-31.

52 Cohen, Configuring the Networked Self, supra n. 27, p. 12 et seq. See also Julie Cohen, "The Regulatory State in the Information Age" (2016) 17 Theoretical Inquiries in Law 369-414.

53 Faraj and Azad take the affordance approach to technological materiality (supra n. 12).

54 Calo, "Can Americans Resist Surveillance?", supra n. 27, p. 34. 
status of the litigants and how this impacts on their ability to access justice), legal anthropology (how institutions and processes of governance affect court procedure and citizens' (dis)incentives to litigate), and architecture (the design of the court's buildings and technical infrastructure and how these affect the mental and physical state of the litigants and their lawyers, in turn affecting the ability of those concerned to present their cases in as effective a way as possible). Each of these is itself a potentially deep and rich enquiry, involving multiple overlapping and contingent affordances and mediations, each shifting according to the particular characteristics of the litigants in question. In short, the claim that "courts afford ways to challenge surveillance" seems both to oversimplify the deeply complex, situated, and contingent realities of such institutions, and to deprive the concept of affordance of substantive analytical content. ${ }^{55}$

Calo later suggests that "we all wind up with the affordances of the accused criminal, who is in certain respects our lowest common denominator." 56 This would seem to demonstrate some of the definitional confusion referred to by Davis and Chouinard, discussed above in part 2.1. Although Calo's ordinary meaning is clear, from the perspective of affordance theory it is not clear who is affording what to whom in this context. We have seen that affordances (and technological mediation more generally) are concerned principally with relationships. The affordance is a relationship between an artefact and an organism (a user). It may also exist between two people, or between two artefacts. In Calo's example, does the criminal accused afford every individual in the

55 As Faraj and Azad suggest, "the affordance perspective is less about intuitive design and more about recognizing the unexpected, situated, and emergent actions that actors may want to engage in with their devices". This would seem to imply the need for a more nuanced treatment of the relationship between an artefact and a user than that which Calo adopts. See Faraj and Azad, supra n. 12, pp. 251-252.

56 Calo, "Can Americans Resist Surveillance?", supra n. 27, pp. 35-36. 
greater population something, in a series of one-to-one relationships? Or is it the accused who is afforded something by the law, or perhaps by the social and/or material processes of the court? Or does his or her experience result in new affordance relationships arising between the institutions of law and individual members of the citizenry? At the very least, there is a lack of clarity here. At worst, adopting the concept at such an abstract level adds little of value to our analysis.

In another recent paper Calo returns to affordance theory in the context of privacy. Again, he invokes law per se as an affordance, but his analysis is unconvincing - he introduces this discussion with the claim, in relation to peopleas-affordances, that "many factors - social, physical, technical, cultural - mediate these affordances" ${ }^{57} \mathrm{He}$ then lists two examples, information and law. On the latter, which he claims is a "'hidden' affordance", he states the following: "the second is the role of law. A trespasser might think your house affords him shelter, a cannibal that your body affords him nutrition. Property and criminal law say otherwise." 58 This belies another confusion. Firstly, affordances are instances of mediation between users and artefacts; they are not themselves mediated (this was discussed above in part 3). ${ }^{59}$ Secondly, can the law in this case (property or criminal, in his example) properly be said to be an affordance per se? Where does it fit into the relationship between the trespasser and the house, or between the cannibal and one's body? I would suggest that the house as a matter of fact affords shelter to the trespasser, and one's body as a matter of fact affords nutrition to the cannibal (or indeed any organism capable of extracting nutrition from human

57 Ryan Calo, “Privacy, Vulnerability, and Affordance” (2017) 66 DePaul Law Review 591-604, p. 601.

58 Ibid., pp. 601-602 (emphasis supplied).

59 See also Kiran and Verbeek, supra n. 35. 
flesh). ${ }^{60}$ That there are other considerations, including the law, is a secondary question; the law does not initially enter the frame, since the affordance relationship is properly between two parties. Rather, in the examples Calo provides there are in fact (at least) two affordance relationships, instead of just one. First, between the human agent (the trespasser or the cannibal) and the artefact (the house or one's body) there exists the affordance to which he refers (one of shelter or of nutrition). Second, between the artefact (again, the house or one's body) and the law (property or criminal) there is perhaps another affordance (in each case 'protection', in the sense that the law affords the artefact protection). Calo's analysis would appear to conflate these two relationships. ${ }^{61}$

Multiple and complex webs of technological (artefact-user) affordances are certainly possible (as discussed above, these are what in aggregate make up technological mediation), but when bundles of affordances are conflated in this way without some finer-grained analysis, it is unclear what value the theory adds. This is particularly true when the affordances are of a different species, as in Calo's examples (technological and legal). It is challenging to strike an appropriate balance between abstraction and particularity; go too far in the latter direction and we might end up with an atomistic view of reality which, while perhaps empirically accurate, provides us with little purchase for the heuristic normative prescriptions the law aims to promulgate. Too abstract, on the other hand, and the theory of affordance ends up doing very little work. This is perhaps

60 This example brings to mind the English case of $R v$ Dudley and Stephens, (1884) 14 QBD 273, and Lon Fuller's "The Case of the Speluncean Explorers" (1949) 62(4) Harvard Law Review 616-645, both of which concern murder and survival cannibalism. In both Dudley and Stephens and in Fuller's fictional story, the very fact the accused parties survived means they were by definition afforded nutrition by the bodies of their unfortunate victims, notwithstanding the legal controversies that ensued (which included, in both cases, their ultimate conviction for murder). The affordance of nutrition and the legal consequences were separate concerns.

61 The proper separation of these two relationships is considered further below in part 5.2. 
one reason to retain the focus on concrete artefactual affordance; if we concern ourselves with the affordance relationships between complex entities that consist of many situated elements ('law', 'court', 'human'), we might end up facing the impossible task of drawing connections between the shifting constituent parts of two moving targets.

Admittedly, Calo does point out in the papers cited above that his discussion is limited in scope, and that he is merely introducing the concept to the legal sphere and only in the context of privacy and surveillance. ${ }^{62}$ Such an introduction is to be welcomed, and there is indeed potential for a more in-depth and wider-ranging discussion on law per se as an affordance (or, rather, set of affordances). One approach to such an analysis might be to treat individual legal norms as 'artefacts', and to query their relationships with particular users (legal persons) from that perspective. Using Davis and Chouinard's affordance mechanisms, it becomes possible to determine what a particular norm requests, demands, allows, encourages, discourages, or refuses of or from a particular user. Whether such an approach would have analytical value is worth exploring. This paper is concerned with the compliance of technological affordances with the law, however, and so this kind of generalised theoretical discussion is outwith its scope. As will be appreciated from the preceding section, however, if the theory is to retain any analytical value it is important to identify clearly who and what is involved in the affordance relationship: there is an important qualitative difference between considering law per se as an affordance, and using affordance theory to deepen our enquiry into the legally-relevant effects of non-legal artefacts.

62 Calo, “Can Americans Resist Surveillance?", supra n. 27, p. 31. 


\subsection{Law as a product of affordance}

Across a range of publications Hildebrandt sets out one such analysis, combining technological affordance with a legal-historical perspective. She charts in detail the development of the technological affordances of text and the printing press, and how these have in turn resulted in what she calls modern law, or "law-aswe-know-it". ${ }^{63}$ Hildebrandt uses technological affordances to chart the evolution of law, going on to elaborate a crucially important warning about how law-aswe-know-it might develop in ways which are antagonistic to constitutional democracy. The methodological novelty is in observing how the affordances of a particular technological embodiment of law, namely printed text, have affected how law has developed in certain ways which have led to the mature and stable set of institutions and concepts we today take for granted. ${ }^{64}$ Her warning concerns how the normative evolution of the law will change as that embodiment shifts from text to "smart technologies": vis-à-vis the law, the affordances of those two embodying technologies, printed text and smart technologies, do not necessarily correspond, and the question is how we can respond to the differences, whatever they may turn out to be. Hildebrandt's concern, with which

63 Mireille Hildebrandt, "Legal Protection by Design: Objections and Refutations" (2011) 5 Legisprudence 223-248. Technology law scholar David Harvey also considers the effect of print on the development of law, discussing the problems that arise when "rules and legal doctrine that were developed and have their foundation in one communications paradigm encounter a new one." See David Harvey, Collisions in the Digital Paradigm: Law and Rule Making in the Digital Age (London: Hart Publishing, 2017), p. 347 and ch. 6 generally. For my review of Harvey's book, see Laurence Diver, "Book Review: Collisions in the Digital Paradigm" (2017) 14:2 SCRIPTed 373-380, available at https://script-ed.org/?p=3422 (accessed 3 February 2018).

64 See Hildebrandt, Smart Technologies, supra n. 3, ch. 8 (particularly the section "8.3.2 The Hallmarks of Modern Law" at p. 176 et seq.); Mireille Hildebrandt and Bert-Jaap Koops, "The Challenges of Ambient Law and Legal Protection in the Profiling Era" (2010) 73 The Modern Law Review 428-460; Mireille Hildebrandt, "A Vision of Ambient Law" in Roger Brownsword and Karen Yeung (eds.), Regulating Technologies: Legal Futures, Regulatory Frames and Technological Fixes (Oxford: Hart, 2008), p. 176; Hildebrandt, "Legal and Technological Normativity", supra n. 30, pp. 171-172. 
it is difficult to disagree, is that the latter embodiment has the potential seriously to undermine those institutions of legality which have become the bedrock of societies built around constitutional democracy. ${ }^{65}$

If we are to heed this warning we need a way of testing for its effects; the ways in which a particular technology affords, or does not afford, the normative elements of modern law are what is in question in Hildebrandt's analyses. The irony is that she deploys the theory of (technological) affordance in her diagnosis of the problem, but not in her prescriptions for a solution, despite technological ("smart") artefacts being both at the core of her concerns, and the quintessential subject for contemporary application of the theory, it having been imported squarely into the world of design by Donald Norman. This absence might be what Calo is referring to when, in his review of Hildebrandt's book, he laments that her argument is not arranged more closely around an overarching theory of affordance, despite her already having "the scaffolding for such a thesis". ${ }^{66}$ Although the value of her application of affordance theory to the diagnosis of the problem is evident, it is curious that she does not continue that method of analysis in her prescriptions for what she calls "legal protection by design" ('LPbD'): she opens the door, but does not step through it.

Text, and the printing press as its enabler, have resulted in the legal system as we know it, complete with the normative commitments which constitutional democracies have been built around and come to rely on. $\mathrm{LPbD}$ is concerned with maintaining those commitments through a sensitivity both to what enabled them to come about, and how they can be sustained, or if necessary re-imagined, in the

65 She states her thesis most succinctly in Hildebrandt, "Law As an Affordance", supra n. 27, p. 119.

66 Ryan Calo, "Technology, Law, and Affordance: A Review of Smart Technologies and the End(s) of Law" (2017) 4 Critical Analysis of Law 72-77, p. 75, available at http://cal.library.utoronto.ca/index.php/cal/article/view/28150 (accessed 3 February 2018). 
new medium in which law is increasingly being embodied. Hildebrandt defines $\mathrm{LPbD}$ as

a way to ensure that the technological normativity that regulates our lives: first, is compatible with enacted law, or even initiated by the democratic legislator; second, can be resisted; and third, may be contested in a court of law. ${ }^{67}$

The question is how to achieve these aims, which Hildebrandt acknowledges represent a "vertiginous challenge to traditional doctrinal research methods within legal scholarship and to the scientific methods of computer science, requirements engineering and electronics." ${ }^{68}$ It is to this end that this exploratory enquiry hopes to contribute. Affordance theory has already assisted Hildebrandt in diagnosing the problem; it has the potential to assist in solving it.

\subsection{Operation versus formation of law}

In a response to a set of reviews of her book Smart Technologies, ${ }^{69}$ Hildebrandt makes explicit an important distinction that I believe is missing, or at least only implicit, in the book itself, between (i) law as an affordance, and (ii) the affordances of law..$^{70}$ Again, the importance of terminology is clear. In the former case, law is the relationship between two entities - the technology of embodiment (text and the printing press) and society. Law does not afford; it is the affordance.

67 Hildebrandt, Smart Technologies, supra n. 3, p. 218. In an earlier paper written with Bert-Jaap Koops, Hildebrandt discusses "ambient law", apparently a precursor term for LPbD, which is defined similarly as "the technological articulation of legal norms as a form of democratic legislation, requiring both democratic participation and built-in safeguards that guarantee the contestability of the decisions made within the legal-technical infrastructure". See Hildebrandt and Koops, supra n. 64, p. 446.

68 Hildebrandt, Smart Technologies, supra n. 3, p. 218.

69 Hildebrandt, Smart Technologies, supra n. 3.

70 Hildebrandt, "Law As an Affordance", supra n. 27. 
Written and printed text have, over time, afforded society or the collective the law-as-we-know-it. This is the dialectical first branch of Hildebrandt's thesis.

In the second branch, law-as-we-know-it has arisen as a set of institutions and processes which, taken together, afford certain things to certain agents. This is the way in which Calo uses the concept, although it bears repeating that in this case the law is not an affordance per se, it is one of the entities between which the affordance relationship arises - the other being the citizen, or the legal person. The institutions of law afford the citizen legality. This is the second branch of Hildebrandt's thesis, from which her central warning flows: how can the law continue to so afford legality, when the affordances upon which its nature in turn rests are themselves changing? The second (non-technological) set of affordances is dependent on the (technological) first: law's affordance of legality to citizens is only possible because of what written and printed text has afforded humanity over the past five centuries. ${ }^{71}$

What if we extend the second branch of Hildebrandt's thesis to continue the analysis of technological affordances, but instead look beyond the formation of law through technological artefacts, towards its daily operation through them? To do so will require a steadfast focus on the relationality of affordance, and if we are to avoid introducing tertiary agents to the relationships so identified, ${ }^{72}$ it might be useful to recast the law as the (mere) user of the technical artefact.

71 This is perhaps a more complex version of what William Gaver terms "sequential" affordances, which "explain how affordances can be revealed over time". See William Gaver, "Technology Affordances", Proceedings of the SIGCHI Conference on Human Factors in Computing Systems (New York, N.Y.: ACM, 1991), pp. 81-82.

72 It could be argued that Calo succumbs to this in his discussion of the affordances of courts, mentioned above, when he invokes more than two parties in his analysis: (i) the law, (ii) the artefact (a court), and (iii) the litigant (or accused). On the value and necessity of viewing technological affordances as relational, rather than as "bundles of features" that are insensitive to the characteristics of the user, see Faraj and Azad, supra n. 12. 
The reason it is the artefact that is used by the law, and not the opposite position, is that the regulatory power of law is fundamentally undermined by the instrumental power of designers. Law's hegemonic grip on the promulgation and enforcement of rules is now profoundly at risk, ${ }^{73}$ and because of this the legal world might benefit from a shift away from a solipsistic and positivist belief in law as both omnipotent and somehow invulnerable to context. ${ }^{74}$ Perhaps nowhere is such a perspective less accurate than in contemporary developed liberal societies, reliant as they have become on privately-ordered, black-boxed technical infrastructures. ${ }^{75}$ For the purposes of applying affordance theory, and perhaps even generally, ${ }^{76}$ we in the legal academy should submit more fully to the (perhaps uncomfortable) idea that the designer of the online artefact is the true sovereign, and the law is, in fact, merely another one of its users.

\section{The law as a user}

\subsection{Code is both more, and less, than law}

In a provocative paper Cornelia Vismann and Markus Krajewski posit that computing architectures are "governmental bureaucracies in miniature", which demonstrate significant structural and authorisational homologies with

73 Hildebrandt, Smart Technologies, supra n. 3, p. 218.

74 Cohen, Configuring the Networked Self, supra n. 27, p. 15 et seq. On the solipsism of the legalistic outlook generally, see Judith Shklar's classic text Legalism (Cambridge, Mass.: Harvard University Press, 1964) et passim. Of course, one cannot suggest that Hildebrandt is guilty of such solipsism, particularly given her willingness to look beyond the traditional boundaries of legal scholarship. Nevertheless, she cautions that she is "a lawyer and a philosopher, rather than an information scientist", so it is perhaps to be expected that the legal side of the equation will take precedence in her analysis. See her "Law As an Affordance", supra n. 27, p. 116.

75 Frank Pasquale, The Black Box Society: The Secret Algorithms That Control Money and Information (Cambridge, Mass.: Harvard University Press, 2015).

76 But without lapsing too far into technological determinism. 
law-as-we-know-it. ${ }^{77}$ In direct reference to online technologies, they write that

[i]nstead of analysing the causes of its impotence, however, the law rather naïvely continues to perceive the Internet as a matter of law, which poses certain problems to the legal order. The law is thus blind to its own dependency on the computer medium as well as to its structural homologies with it. ${ }^{78}$

Law is instantiated in and by the technological artefact, and while those artefacts are themselves constituted to some extent by pre-existing legal precepts, in dayto-day operation the relationship is lopsided. Both law and technical artefacts and infrastructures "control mechanisms of inclusion and exclusion, access and nonaccess", ${ }^{79}$ but owing to a hermeneutic 'gap', where law on the page requires interpretation to alter behaviour in the real world, legal norms are not nearly as powerful as we might suppose (or wish) when operating in the technical context. ${ }^{80}$ The immediacy and instrumental power of that medium and the

77 Vismann and Krajewski, supra n. 1. The quote is in turn borrowed from Friedrich Kittler. See his "Protected Mode" in John Johnston (ed.), Stefanie Harris (tr.), Literature, Media, Information Systems: Essays (Amsterdam: Psychology Press, 1997), in which he invokes Michel Foucault's concept of power as "action upon action", suggesting that one should "abandon the usual practice of conceiving of power as a function of so-called society, and, conversely, attempt to construct sociology from the chip's [CPU's] architectures." (p. 162). For Foucault's discussion of power, see his "The Subject and Power" (1982) 8 Critical inquiry 777-795.

78 Vismann and Krajewski, supra n. 1, p. 92. One can appreciate the connection here with Hildebrandt's discussion of law's embodiment in a particular technological medium.

79 Ibid., p. 91. Here we can detect echoes of Davis and Chouinard's affordance mechanisms (supra n. 23).

80 Hildebrandt calls this gap the "underdeterminacy" of (text-based) law. See Hildebrandt, "Legal and Technological Normativity", supra n. 30, p. 177. Legal philosophers Zenon Bańkowski and Neil MacCormick suggest that without such a gap to enable a "principled approach to interpretation", legality collapses into legalism. See Zenon Bańkowski and Neil MacCormick, "Legality without Legalism" in Werner Krawietz et al. (eds.), The Reasonable as Rational? On Legal Argumentation and Justification; Festschrift for Aulis Aarnio (Berlin: Duncker \& Humblot, 2000), p. 194. 
implied sovereignty of the designer tip the balance inexorably away from law as hegemonic creator and regulator of reality. ${ }^{81}$ While the law continues to constitute a form of reality through legal facts, when faced with the instrumental juggernaut of architectural constitutionality its power is eviscerated. ${ }^{82}$ The written law is but "a paper dragon in the age of the "digital tsunami'"; 83 the social and rhetorical power of legal fictions make way for the representationalism of "digital virtuality" through which reality is by definition constituted by and through the machine. ${ }^{84}$ As Bruno Latour suggests, with the advent of computers "we are able to conceive of a text (a programming language) that is at once words and actions"; $; 85$ when the text of the rule on the 'page' is source code, it no longer requires an interpretative step to constitute reality. ${ }^{86}$ The end result is the collapse of adjudication into compliance. ${ }^{87}$

Technological mediation, and individual affordances as its building blocks, very literally "subject human conduct to the governance of rules". ${ }^{88}$ To a greater or lesser degree, the commercial entities which define that mediation and

81 James Grimmelmann sets out a useful taxonomy of the regulative characteristics of software, arguing that its particularities mean it is a sui generis mechanism of regulating behaviour that is qualitatively different from Lessig's more diffuse 'architecture'. See James Grimmelmann, "Regulation by Software" (2005) 114 The Yale Law Journal 1719-1758. On the latter, see Lessig, supra n. 18, ch. 7.

82 This relates to Hildebrandt's discussion of constitutional versus regulative norms, and the relationships of the "twin sisters" of technological and legal normativity. See Hildebrandt, "Legal and Technological Normativity", supra n. 30.

83 Hildebrandt and Koops, supra n. 64, p. 440.

84 Vismann and Krajewski, supra n. 1, p. 92.

85 Latour, supra n. 36, n. 1.

86 Of course, source code does in fact require either to be interpreted or compiled by an additional application in order to be executed. Assuming the code is syntactically sound, however, it is for all practical purposes isomorphic with the running software.

87 Zenon Bańkowski and Burkhard Schafer, "Double-Click Justice: Legalism in the Computer Age" (2007) 1 Legisprudence 31-49, p. 48.

88 This quote is Lon Fuller's definition of law, taken from his influential The Morality of Law (New Haven, Conn.: Yale University Press, 1977) et passim. 
those affordances thus exercise sovereign-like power over users. ${ }^{89}$ As Lessig puts it, "[a]rchitecture is a kind of law: it determines what people can and cannot do. When commercial interests determine the architecture, they create a kind of privatized law." ${ }^{90}$ The power that inheres in those who decide that private ordering is significant:

The quasi-sovereign power of the computer engineer's code stems from the ease by which posing, implementing, and applying a norm are achieved in technology compared with the cumbersome procedures that legal code must pass through. The swift effectiveness of a technological code, which cannot, when seen through legal eyes, appear as anything other than uncanny, renders any possible competition between law and computer pointless. ${ }^{91}$

Technical artefacts are not just law-like, they are simultaneously both more, and less, than law. More, because their instrumental power is far greater, owing to the representationalism of software code which necessarily becomes reality, collapsing the hermeneutic gap. Less, because, as Hildebrandt observes, they lack the normative mechanisms that keep their textually-bound legal sister in check.

Vismann and Krajewski's juridification of technical architectures runs even deeper than this. They posit the role of a "programmer of the programmer" ('PoP'), who sits earlier in the design chain, enforcing architectural compliance on the designer of the user-facing technological artefact. ${ }^{92}$ The PoP does this through the design of chip architectures, programming languages, and

89 Nagy and Neff, supra n. 12, p. 4. As Grimmelmann suggests in relation to social networking platforms, "sovereigns of software have absolute and dictatorial control over their domains." See James Grimmelmann, "Anarchy, Status Updates, and Utopia" (2014) 35 Pace Law Review 135-153, p. 135.

90 Lessig, supra n. 18, p. 77.

91 Vismann and Krajewski, supra n. 1, p. 93 (my emphasis).

92 Ibid., p. 100. 
integrated design environments, creating the underlying constitutional setting within which the product designer must herself operate. The mediation of the user's reality is preceded by the mediation of the designer's; how the PoP architects the languages and tools with which consumer artefacts are designed creates a backdrop of mediation and affordance that affects and channels the underlying mechanisms of artefact production.

A parallel thus begins to emerge between the legal public and the technological private: the mediating decisions of the PoP create fundamental rules (a 'constitution') which constrain and enable the activities of designers within their development environments ('parliament'), which in turn affect the design-rule choices that are subsequently made ('legislation') and how these affect the user ('citizen'). Without dwelling too long on the metaphor of the PoP, it hopefully adds some depth to the understanding of how easily legal constitutions are supplanted by their technological counterparts. ${ }^{93}$

\subsection{The mediation of law by technological artefacts}

The first step in ameliorating the blindness of law referred to by Vismann and Krajewski is for it to accept the uncomfortable realities of its place in the power structures being fomented by online artefacts and infrastructures. Only then can it begin to respond intelligently to the material practices, and commercial incentives, of those who design and implement those technologies. Hildebrandt's $\mathrm{LPbD}$ represents a major push towards this realisation. ${ }^{94}$ The question is where

93 On the quasi sovereignty and quasi legislative and executive power of online intermediaries, and their ability to "autonomously implement their self-defined regulations via technical means", see Luca Belli and Jamila Venturini, "Private Ordering and the Rise of Terms of Service as Cyber-Regulation" [2016] 5(4) Internet Policy Review 1-17, p. 4.

94 Hildebrandt is not the first to have considered this problem, but within the legal literature her engagement with design theory is perhaps the most in-depth to date. The literature on the threat to legality with respect to technological enforcement includes, for example, Cohen, 
to go next. Her analysis relies on affordance (and, tangentially, mediation) to diagnose the problem, but only in passing does she refer to how LPbD might be achieved. ${ }^{95}$ With awareness of affordance theory introduced to the legal fold, we have the beginnings of a methodology that can address 'sovereign' designers on their own terms.

When technical artefacts create legal effects, ${ }^{96}$ they mediate the operation of law through their mediation of reality. The artefact becomes the means through which the law-as-a-system operates in the world. Let us consider digital rights management (DRM) systems, and specifically those involved in the Sony BMG scandal in the mid-2000s. The system in that case was designed to concretise copyright law so that users were unable to behave in ways contrary to it. Taking the perspective of law-as-user, copyright's purposive aim was to endow the rightholder (in this case Sony BMG) with the absolute right to control who is permitted to make copies of the CDs in question. In terms of Davis and Chouinard's affordance mechanisms, the affordance the law was looking for was one of refusal. For most users, the technical instantiation of the relevant law by the two DRM systems fulfilled this affordance.

"The Regulatory State in the Information Age", supra n. 52; Pasquale, supra n. 75; Roger Brownsword, "In the Year 2061: From Law to Technological Management" (2015) 7 Law, Innovation and Technology 1-51; Kenneth Bamberger, "Technologies of Compliance: Risk and Regulation in a Digital Age" (2010) 88 Texas Law Review 669-739; Danielle Citron, "Technological Due Process" (2007) 85 Washington University Law Review 1249-1313.

95 Hildebrandt and Koops discuss "transparency-enhancing technologies" as one potential, but only in the context of data protection and user profiling. See Hildebrandt and Koops, supra n. 64, p. 449 et seq.

96 Automated decision-making systems that have "legal effects" vis-à-vis data subjects are explicitly regulated under art. 22 of the EU's GDPR (Regulation on the protection of natural persons with regard to the processing of personal data and on the free movement of such data, and repealing Directive 85/46/EC (General Data Protection Regulation) 2016). Of course, that instrument is concerned with data protection, while the present discussion takes a more holistic view of law-as-a-system. 
But the system was (famously) not fool-proof - users with even minimal technical knowledge could easily circumvent the system by preventing the thenstandard 'autorun' feature of Windows operating systems. ${ }^{97}$ The mediation of law through the mediation of reality then reduces to mere discouragement at best, and allowance at worst: by affording the user copying, the law is not afforded isomorphism by the artefact (in the form of an architecturally instrumentalised blanket prohibition on copying).

The artefact mediates both reality for the user, and the substantive law. Law's reality is transformed by the technical artefact in the way in which it coconstitutes the user's reality. Returning to the model from above, in the case of the Sony BMG DRM the technological mediation of law $\left(\mathrm{TM}_{(\mathrm{law})}\right)$ did not match

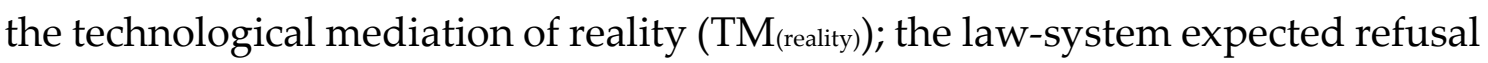
of copying, and the reality for the user as co-constituted by the artefact was not isomorphic with this - she was able easily to make such copies.

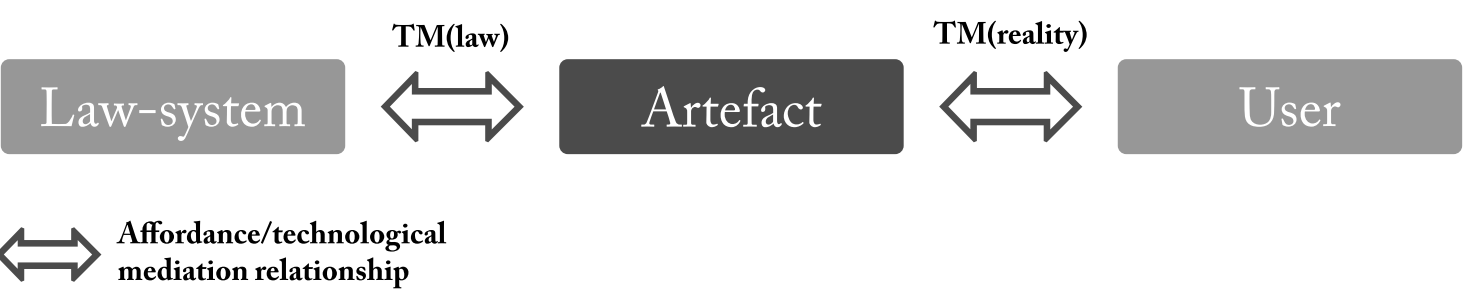

Figure 2. Law-system $\leftrightarrow$ Artefact $\leftrightarrow$ User relationships of technological mediation

That fact that many users will have been unaware of the easy work-around means that their reality matched the law; $\mathrm{TM}_{\text {(law) }}$ and $\mathrm{TM}_{\text {(reality) }}$ were isomorphic, and their behaviour was constrained as expected. The extent to which the law can tolerate non-compliance will vary between norms, depending on the aims of

97 Mulligan and Perzanowski, supra n. 20, p. 1202 and n. 206. 
the legislator and the seriousness of the ill it is designed to avoid. By positioning the law as a user in this way, the law-system looks for certain characteristics in the technology in and through which it is embodied, much like a human user does when she wants to achieve something with a particular online artefact. ${ }^{98}$

By enquiring as to the expectations of the legal norm, and how the technical artefact can meet those expectations (how it can afford them), we can think about how to improve architectures during the early stages of a product's design. This is in line with initiatives like the EU law-mandated data protection by design and by default, which requires data controllers to implement "appropriate technical and organisational measures" in their design processes so as to implement the data protection principles. ${ }^{99}$ Depending on how the expectations of the law are couched for the purposes of affordance (either in terms of the substantive content of the norm, or towards more diffuse principles of legality, akin to $\mathrm{LPbD}^{100}$ ), we as lawyers can engage directly with the design world on its own terms. Building a narrative around an imagined user persona is common practice in design processes, ${ }^{101}$ but since the law is (at least in the mid-

98 As Faraj and Azad put it, affordance is "a relational construct linking the capabilities afforded by technology artifacts to the actors' purposes". See Faraj and Azad, supra n. 12, p. 254. See also Maier and Fadel, supra n. 11, p. 3 ("2.4 The Fundamental Affordance Relationship"), where the authors discuss how affordances are manifestations of new behaviours which the constituent user/artefact cannot produce alone. Considering a legal norm as an 'actor' in this way accords with the ANT method of viewing non-humans as 'actants', giving them equal agency in the process of transformation which results in hybrid human/non-human 'actors'. See Latour, supra n. 35, p. 159 and n. 11.

99 GDPR, supra n. 96, art. 25. This initiative has a long history, originating with 'privacy by design' in the 1990s. See Ann Cavoukian, “Privacy by Design: Origins, Meaning, and Prospects for Assuring Privacy and Trust in the Information Era" in George Yee (ed.), Privacy Protection Measures and Technologies in Business Organizations: Aspects and Standards: Aspects and Standards (Pennsylvania: IGI Global, 2012).

100 Some tensions that arise when choosing a point on this spectrum are explored by Hildebrandt in Hildebrandt, "Legal Protection by Design", supra n. 63.

101 Benjamin Bratton, The Stack: On Software and Sovereignty (Cambridge, Mass.: MIT Press, 2016), pp. 254-255; Nagy and Neff, supra n. 12, p. 4; Chris Ivory, "The Role of the Imagined User in Planning and Design Narratives" (2013) 12 Planning Theory 425-441. 
term) a fixed entity in a way a real user is not, identifying its requirements and how the artefact might afford it compliance is perhaps a less complicated task. ${ }^{102}$ The mode of thinking which affordance theory foments is apt to identify what an artefact in fact does, over and above its intended function. ${ }^{103}$ Looked at from a compliance perspective, external legally-problematic effects might thus be avoided, for example the privacy invasion occasioned by the Sony BMG DRM systems. ${ }^{104}$ The latter is a negative affordance in the Gibsonian sense, from the perspectives of both the law-as-user and the human user: the law, and constitutional democracy more generally, are 'injured' by non-compliance; the human by her privacy being undermined.

Approaching the compliance by design conundrum from such a perspective means the designer is not wrenched from her natural habitat and expected to become a quasi-lawyer; rather she can work with the conceptual tools of her trade, as can those in the legal world. ${ }^{105}$

\section{Conclusion}

The application of affordance theory in the legal realm has promise, but as it develops this nascent literature must be careful to avoid the pitfalls of definitional confusion and overbroad application warned of in the design sphere.

102 For a critical perspective on the problematic reductionism of imagined human (as opposed to legal) users, see Adrienne Massanari, “Designing for Imaginary Friends: Information Architecture, Personas and the Politics of User-Centered Design" (2010) 12 New Media \& Society 401-416.

103 See Maier and Fadel, supra n. 45, p. 24, where the authors argue that an affordance-based analysis "forces the designer to think about what else a particular embodiment affords besides providing its intended function (in particular the early identification of negative affordances)."

104 See Mulligan and Perzanowski, supra n. 20 et passim. On the conflict between DRM and privacy generally, see Julie Cohen, "DRM and Privacy" (2003) 46 Communications of the ACM 46-49.

${ }^{105}$ Maier and Fadel, supra n. 45, p. 24. 
The present contribution aims to avoid some of these problems by maintaining a focus on the relational structure of affordance theory, and of technological mediation more generally. Through an appreciation of the instrumentality of technological architectures, which renders the previously hegemonic law merely another 'user' of those architectures, we can begin to come to terms with law's diminished position, and to ask the difficult questions required to uphold its normative aims and structures. Casting the law as a user in this way both recognises its status vis-à-vis code, and enables it to fit into the relational schema of affordance and mediation theory. From there, our critical assessments of the technological architectures which mediate the operation of law can be better attuned to both the material realities of architectural regulation, and the contexts within which the power of the new designer-sovereigns is wielded.

\section{Acknowledgements}

I would like to thank three anonymous reviewers for their insightful and constructive feedback on an earlier draft. I would also like to thank Professors Burkhard Schafer and Lilian Edwards for our discussions on this and many other topics. 